\title{
ERRATUM
}

\section{Erratum to: Promotion of Chondrogenesis of Marrow Stromal Stem Cells by TGF-ß3 Fusion Protein In Vivo*}

Wei WU (吴薇 $)^{1 \dagger}$, Yang DAN (但 洋 $)^{2 \dagger}$, Shu-hua YANG (杨述华 $)^{2}$, Cao YANG (杨 操 $)^{2}$, Zeng-wu SHAO (郡增务 $)^{2}$, Wei-hua XU (许伟华 $)^{2}$, Jin LI (李 进) ${ }^{2}$, Xian-zhe LIU (刘先哲) $)^{2}$, Dong ZHENG (郑 东) ) $^{2 \text { Z }}$

${ }^{I}$ Department of Pediatrics, Tongji Hospital, Tongji Medical College, Huazhong University of Science and Technology, Wuhan 430030, China

2 Department of Orthopedics, Union Hospital, Tongji Medical College, Huazhong University of Science and Technology, Wuhan 430022, China

(C) Huazhong University of Science and Technology and Springer-Verlag Berlin Heidelberg 2013

Erratum to: J Huazhong Univ Sci Technol [Med Sci]

DOI 10.1007/s11596-013-1182-Z

The original version of this article unfortunately contained a mistake. The presentation of the title was incorrect. The corrected title is given below.

Promotion of Chondrogenesis of Marrow Stromal Stem Cells by TGF-ß3 Fusion Protein In Vivo

The online version of the original article can be found at http://dx.doi.org/10.1007/s11596-013-1182-z

Wei WU, E-mail: Wuweir11@163.com; Yang DAN, E-mail: Yang.Dan.daniel@gmail.com

These authors contributed equally to this work.

${ }^{\#}$ Corresponding author, E-mail: xhzhengdong@163.com

${ }^{*}$ This project was supported by the National Natural Science Foundation of China (No. 81101376). 